\title{
OTOMOBÍLLERDE ÖN ÇARPIŞMA KOLU MALZEMESİ OLARAK FEE340 VE DP600 MALZEMELERIN ÇARPIŞMA PERFORMANSLARININ KARŞILAŞTIRILMASI
}

\author{
Fahri Berk BILLA $Y^{*}$ \\ Murat REIS \\ Betül G̈̈LÇIMEN ÇAKAN* \\ Mustafa Cemal ÇAKIR *
}

Alınma: 06.12.2018 ; düzeltme: 14.02.2019 ; kabul: 26.03.2019

\begin{abstract}
Öz: Bu çalışmada, otomotiv endüstrisinde çok sık kullanılan iki farklı çelik malzeme için yarım araç modeli kullanılarak önden çarpışma senaryosu (rijit duvar testi) bilgisayar ortamında simule edilmiştir. Ön çarpışma kollarında kullanılan HSLA (High-Strength Low-Alloy) çelik ailesi grubundaki FEE340 ve DP (Dual Phase) çelik ailesi grubundaki DP600 malzemelerinin aracın çarpışma performansına olan etkileri karşılaştırılmışıtır. Modeldeki ön tampon traversi, çarpışma kutusu ve çarpışma kolu Siemens NX yazılımı kullanılarak tasarlanmıştır. Tasarlanan çarpışma elemanlarının ön işleme prosesi, Altair Hypermesh yazılımı kullanılarak yapılmış ve dinamik analize hazır hale getirilmiştir. Modelin dinamik analiz senaryosunu oluşturmak ve analizin çözümü için Abaqus yazılımı kullanılmıştır. Simülasyonlardan, her bir eleman tarafindan sönümlenen enerji miktarı, oluşan toplam yer değiştirme, yolcu kabinine iletilen yük miktarı ve çarpışma kuvveti verimliliği (CFE) sonuçları elde edilmiştir. Bu veriler baz alınarak malzemelerin aracın çarpışma performansına etkileri değerlendirilmiş ve sonuç olarak FEE340 ve DP600 malzemelerinin CFE katsayıları yakın çıkmasına karşın FEE340 malzemesinin yolcu kabinine ilettiği kuvvetin \%32 daha az, oluşturduğu yer değiştirme miktarının \%11 daha fazla olduğu görülmüştür.
\end{abstract}

Anahtar Kelimeler: çarpışma analizi, sonlu elemanlar, ön çarpışma kolu, FEE340, DP600

\section{Crush Performance Comparison of FEE340 and DP600 Materials as Front Collision Rail in Automobiles}

\begin{abstract}
In this study, a frontal collision scenario (rigid wall test) is simulated in a computer environment using a half vehicle model for two different sheets of steel that are frequently used in automotive industry. The effects of materials, namely FEE340 steels in HSLA (High-Strength Low Allow) family and DP600 steels in DP (Dual Phase) family compared as front collision rails on crash performance of a vehicle. Front bumper cross member, crash box and collision rail in the model were designed using Siemens NX software. The pre-processing stage of collision elements before the dynamic analysis was carried out using Altair Hypermesh software. Abaqus software was used to create the dynamic analysis scenario of the model and to solve the analysis. The amount of energy absorption by each element, the total displacement, the level of the load transferred to the passenger compartment and the crush force efficiency (CFE) results were obtained from the simulations. According to the simulations results, although the CFE coefficients of FEE340 and DP600 materials are close, when the FEE340 material was used, the force transferred to the passenger compartment was $32 \%$ less, and the total displacement was $11 \%$ higher.
\end{abstract}

\footnotetext{
* Uludağ Üniversitesi, Mühendislik Fakültesi, Makine Mühendisliği Bölümü, Görükle Kampüsü, 16059 Bursa

İletişim Yazarı: Fahri Berk BİLBAY (bilbayberk@gmail.com)
} 
Keywords: Crush analysis, finite element method, front collision rail, FEE340, DP600

\section{GíRIŞ}

Otomotiv gövde elemanları, araç tasarımına, ağırlığına ve en önemlisi de güvenliğine etki eden yönleri itibariyle otomobili oluşturan sistemler arasında en önemli rolü oynamaktadır. Araç gövde elemanlarından temel beklenti, yüksek burulma direncine sahip olmasiyla kullanıcıyı engebeli yollarda rahat hissettirmek, araca gelebilecek titreşimlerin engellenmesini sağlamak ve yüksek enerji emme kabiliyetine sahip olmasıyla kaza anında önden, yandan veya arkadan çarpışma sonucu oluşabilecek kuvvetleri en iyi şekilde sönümleyerek sürücüyü oluşabilecek darbelerden korumasıdır.

Ön çarpışma kolları, çarpışma anında açığa çıkan kinetik enerjinin yaklaşık \% 60 - 70'inı sönümleyen yapısal elemanlardır (Ghannam ve diğ., 2002). Bu elemanlar çok rijit olursa yolcu kabinine iletilen kuvvetin değeri de yüksek olacaktır. Öte yandan çarpışma kollarının düşük mukavemetli olması, yer değiştirme miktarını artırarak, yolcu yaşam kafesine girişimler meydana gelmesine sebep olabilir. Bu nedenle çarpışma esnasında araç gövde elemanlarından temel beklenti, belirli bir miktarda yer değiştirmeye izin vererek, açığa çıkan enerjiyi yolcuya en az hissettirecek bir şekilde sönümlemesidir.

Otomotiv güvenliği ile ilgili 1990'lı yıllardan sonra çok önemli gelişmeler yaşanmış ve yolcu güvenliği otomotiv üreticileri için bir pazarlama özelliği haline gelmiştir. Standartlaştırılmış çarpışma testleri ile ölçülen araç dayanıklılı̆̆ı, en az kalite, stil, sürüş, kullanım ve yakıt ekonomisi kadar önem kazanmıştır (Bols ve diğ., 2004, Ensarioğlu ve diğ., 2018, Gülçimen ve diğ., 2018). Son yıllarda otomotiv güvenlik sistemleriyle ilgili yapılmış çok sayıda deney ve sonlu elemanlar çalışması vardır. Ghannam ve diğ . $(2002)$ çarpışma kollarının kesit ve kalınlığını optimize elde etmek için yaptıkları çalışmada $15,65 \mathrm{~m} / \mathrm{s}$ hızındaki rijit bariyeri, dikdörtgen ve konik kesitlerdeki, farklı kalınlığa sahip çarpışma kollarına çarptırmıştır. Sonuç olarak konik forma sahip çarpışma kolu kullanımı ile enerji emiliminde \% 45 e varan iyileşme gözlenmiştir. Chiandussi ve diğ. (2002) konik yapılı darbe emicilerin maksimum enerji sönümlemesi ve minimum tepki kuvvetine göre konik bölgenin şeklini optimize etmiştir. Edwards ve diğ. (2003) çarpışma test prosedürlerini geliştirmek maksadıyla farklı hızlarda çarpışma senaryoları oluşturmuş ve çarpışma hızına bağlı olarak kabine iletilen maksimum kuvvet değerlerini vermiştir. Eren ve diğ. (2008) çarpışma kollarında açığa çıkan pik kuvveti düşürmek için çarpışma kolunun ön kısmında 3 farklı ezilme başlatıcı (collision initator) form ve 4 farklı kesit geometrisi denemiştir. Dairesel kesit ile diğer geometriler arasında pik kuvvet açısından kayda değer bir fark olmadığı fakat sönümlenen enerji miktarının dairesel kesitte \% 10 - 40 daha fazla olduğu gözlenmiştir. Öztürk ve diğ. (2008) araçlarda güvenlik elemanlarından birisi olan tampon ve darbe emici modeli üzerinde çarpışma analizleri yapmış ve darbe emiciler üzerinde burkulma başlatıcı bölgelerin etkisi incelenmiştir. \% 40 ofsetli bir çarpışma modeli için analiz sonuçları inlemiş, burkulma başlatıcı bölge sayısının absorbe edilen enerji miktarına önemli derecede etkisi görülmemiş ancak maksimum tepki kuvvetini azalttığ 1 gözlenmiştir. Liu ve diğ. (2010) minibüslerde ön çarpışma kolunun en uygun kesitini, malzemesini ve et kalınlığını belirlemek için bilgisayar simülasyonları gerçekleştirmiştir. Ön çarpışma kolu farklı geometrik şekillerde, LC4 ve $16 \mathrm{MnL}$ malzemeleri kullanılarak simule edilmiş ve altıgen kesitli profilin kare kesitli profile göre daha fazla enerji sönümlediği, 16 MnL'nin LC4 malzemesine göre daha iyi sonuçlar verdiği belirtilmiştir. Tahan ve diğ. (2013) araçlarda kütle değişiminin çarpışma performansına etkisini incelemek amaciyla sonlu elemanlar metodu kullanmıştır. Simülasyonlarda, dört farklı kütleye sahip araç modelini 64 $\mathrm{km} / \mathrm{h}$ ve $\% 100$ ofsetli bariyer ile çarptırmıştır. Araç kütlesine bağlı olarak yolcu kabini ivmesinin $47 \mathrm{~g}$ ile $53 \mathrm{~g}$ arasında değiştiği gözlenmiştir. George Mason Üniversitesi (2016) Toyota Yaris modeli aracın çarpışma sonuçlarını sunum olarak yayınlamıştır. Yayınlanan sunumda $\% 100$ ofsetli ve $56 \mathrm{~km} / \mathrm{h}$ hızındaki araç rijit duvara çarptırılmış ve yolcu kabinine iletilen kuvvet, yer değiştirme miktarı ve ivme eğrileri paylaşılmıştır. Aracın ön uç noktasının 
toplam $550 \mathrm{~mm}$ yer değiştirdiği ve kabine iletilen maksimum kuvvetin $575 \mathrm{kN}$ olduğu görülmüştür. Yolcu kabininin maksimum yavaşlama ivmesi ise $50 \mathrm{~g}$ olarak ölçülmüsştür.

FEE340 malzemesi içerisinde düşük yoğunlukta alaşımların olduğu bir yapıya sahip HSLA grubu bir çeliktir. Yüksek mukavemet ve düşük ağırlık istenilen durumlarda HSLA (High Strength Low Alloy) grubu çelikler ön plana çıkmaktadır (Ramazani ve diğ., 2014). DP600 malzemesi ise yumuşak ferrit matriksi içerisinde 5\% - 20\% sert martenzit, bulunan çift fazlı yapıya sahip bir çeliktir. Çift fazlı çelikler, iyi form alma kabiliyetleri sayesinde otomotiv endüstrisinde en çok kullanılan yüksek dayanımlı çeliklerdir. Fekete ve diğ. (2001) çarpışma kolu malzemesi olarak HSLA ve DP çelik ailesi grubuna sahip iki farklı çelik kullanmıştır. 24 $\mathrm{km} / \mathrm{h}$ ve $46 \mathrm{~km} / \mathrm{h}$ hızlarında iki farklı test senaryosu oluşturmuş ve çarpışma kollarındaki çarpışma performansını incelemek için "drop tower" testini uygulamıştır. DP çeliğinin HSLA çeliğine göre kütle başına yaklaşık \%10 daha fazla enerji absorbe ettiği gözlenmiştir.

Bu çalışmada, otomotiv endüstrisinde çok sık kullanılan iki farklı çelik malzeme için yarım araç modeli kullanılarak önden çarpışma senaryosu (rijit duvar testi) bilgisayar ortamında simule edilmiştir. Bu çalışmada literatürden farklı olarak, ön çarpışma kolunun ön kısmındaki tüm çarpışma elemanları ve bunların bağlantı şekilleri detaylı olarak modellenmiştir. Çalışma üç bölümden oluşmaktadır. İlk bölümde tasarım ve malzeme modelleri tanıtılmakta, simülasyon verileri ve kısıtlar belirlenmekte ve çarpışma senaryosu oluşturulmaktadır. İkinci bölümde FEE340 ve DP600 malzemeleri için simülasyon sonuçları enerji sönümleme eğrileri, toplam yer değiştirme eğrisi, yolcu kabinine iletilen kuvvet eğrileri ve ön çarpışma kollarının çarpışma kuvvet verimliliği (CFE) eğrileri ile verilmiştir. Son bölümde simülasyon sonuçları değerlendirilmiştir.

\section{MATERYAL VE YÖNTEM}

\section{1. Ön Çarpışma Bölgesinin Tasarım Aşaması}

Ön çarpışma bölgesi elemanları; ön çarpışma kolu, çarpışma kutusu, ön çarpışma kolunu çarpışma kutusu ile bağlayan flanşlar ve ön tampon destek traversi Siemens NX bilgisayar destekli tasarım yazılımında Şekil 1'deki gibi tasarlanmıştır.

FEE340 ve DP600 malzemelerinin kullanıldı̆̆ her iki modelde de ön tampon traversinde ve çarpışma kutusunda $2,5 \mathrm{~mm}$ et kalınlığında 6060 serisi alüminyum malzeme, çarpışma kutusu tarafı flanşta $3 \mathrm{~mm}$ et kalınlığında 6060 alüminyum malzeme, çarpışma kolu tarafı flanşta $3 \mathrm{~mm}$ et kalınlığında DP600 malzeme kullanılmıştır. Çarpışma kollarında ise 2,6 mm et kalınlığında iki farklı plastik şekil değiştirme eğrisine sahip FEE340 ve DP600 malzemeler kullanılmıştır.

Şekil 2'de görüldügü gibi ön çarpışma bölgesi elemanlarının $X$ ve $Z$ eksenlerindeki boyutları verilmiştir. Ön çarpışma kolu geometrisi yapılan literatür araştırmaları sonucu kare şeklinde $800 \times 80 \times 80 \mathrm{~mm}$ olarak tasarlanmıştır (Liu ve diğ., 2010). Çarpışma kutusunun boyutları, 184 × $100 \times 85 \mathrm{~mm}$ ve ön tampon traversinin boyutları $105 \times 1525$ x $85 \mathrm{~mm}$ olacak şekilde tasarlanmıştır.

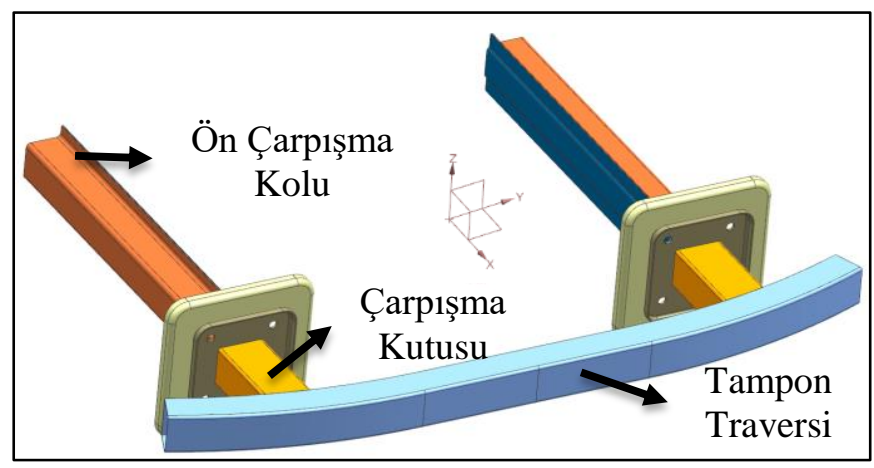


Şekil 1:

Araç ön çarpışma bölgesinin 3 boyutlu geometrisi

\begin{tabular}{|c|c|c|c|c|}
\hline & 105 & 184 & 800 & \\
\hline$\infty$ & \begin{tabular}{l|l} 
Tampon \\
Traversi
\end{tabular} & $\begin{array}{l}\text { Çarpıssma } \\
\text { Kutusu }\end{array}$ & Çarpışma Kolu & $\stackrel{\infty}{\circ}$ \\
\hline
\end{tabular}

Şekil 2:

Araç ön çarpışma bölgesinin 2 boyutlu geometrisi

\section{2 Ön Çarpışma Bölgesinin Ön İşlem Prosesi}

Ön çarpışma bölgesi tasarımı, Altair Hypermesh (Abaqus/Explicit) bilgisayar destekli mühendislik yazılımı kullanılarak modellenmiştir. Ön çarpışma bölgesi elemanları olarak S3R ve S4R tipinde, $5 \mathrm{~mm}$ boyutunda kabuk eleman yapıları oluşturulmuştur. Modelde toplam 66265 adet kabuk eleman ve 67306 adet düğüm mevcuttur.

Şekil 3'te görüldüğü gibi ön tampon traversi - çarpışma kutusu, çarpışma kutusu çarpışma kutusu tarafındaki flanş ve çarpışma kolu - çarpışma kolu tarafindaki flanş arasında tüm eksenlerde hareketsiz rijit elemanlar tanımlanarak kaynak bölgeleri oluşturulmuştur. Çarpışma kutusunu ve çarpışma kolunu birbirine bağlayan flanşlara 4 adet civata bağlantısı Şekil 3 'te görüldüğü gibi ankastre tipinde deliğin etrafındaki tüm düğümlerden sabitlenmiştir.

\section{3 Ön Çarpışma Bölgesi Sonlu Elemanlar (Explicit) Analizi}

Ön çarpışma bölgesinin çarpışma senaryosu Abaqus yazılımında oluşturulmuştur. FEE340 ve DP600 malzemelerinin elastik ve plastik özellikleri yazılımda tanımlanmıştır. Her iki modelde kullanılan çelik malzemelerin yoğunlukları $7,86 \mathrm{~g} / \mathrm{cm}^{3}$, elastisite modülleri $210 \mathrm{GPa}$ olarak, alüminyum malzemenin yoğunluğu $2,7 \mathrm{~g} / \mathrm{cm}^{3}$, elastisite modülü $68 \mathrm{GPa}$ olarak tanımlanmıştır. Her iki malzemenin plastik şekil değiştirme eğrileri Şekil 4'te verilmiştir.

Ön çarpışma bölgesine çarptırılacak rijit duvara aracın kütlesine eş $1000 \mathrm{~kg}$ kütle tanımlanmıştır. $64 \mathrm{~km} / \mathrm{h}$ hıza ve $1000 \mathrm{~kg}$ kütleye sahip rijit duvarda oluşan kinetik enerji aşağıdaki gibi elde edilir.

$$
\begin{gathered}
E_{k}=\frac{1}{2} \times m \times V^{2} \\
E_{k}=\frac{1}{2} \times 1000 \times 17,77^{2}=162 \mathrm{~kJ}
\end{gathered}
$$

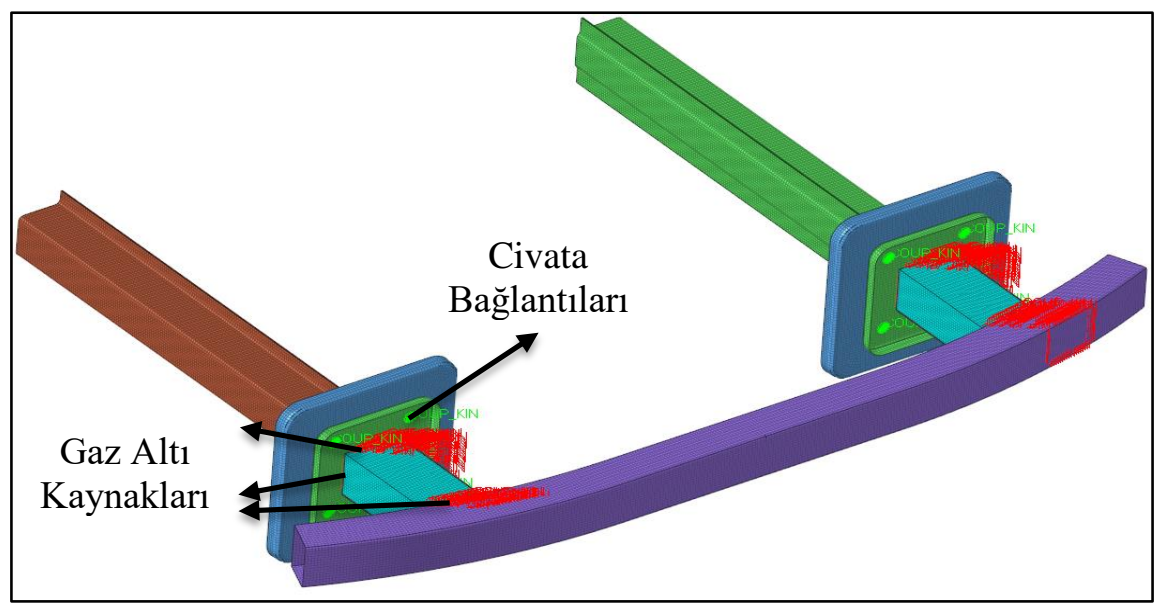


Şekil 3:

Ön çarpışma bölgesinin ön işleme proses modeli (Hypermesh-Abaqus)

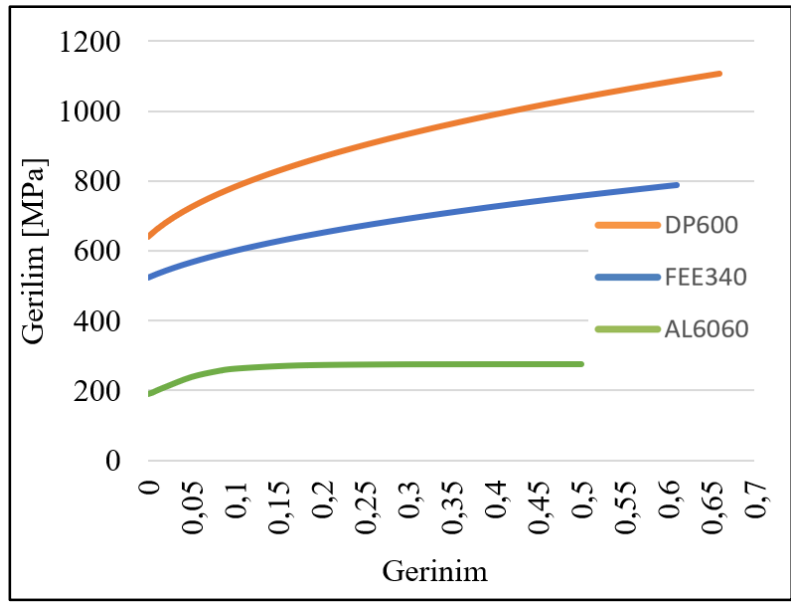

Sekil 4:

FEE340, DP600 çeliklerinin ve AL6060 alüminyumun plastik şekil değiştirme eğrileri

Çarpışmanın analizinde zaman adımı, analizin çözüm süresi ve güvenilirliği açısından önemli bir faktördür. Literatürden önden çarpışma senaryolarında adım sürelerinin $120 \mathrm{~ms}$ civarında belirlendiği görülmüştür (Deb ve diğ., 2015). Bu nedenle bu çalışmada, çarpışma kollarında FEE340 ve DP600 malzemesine sahip her iki model de 120 ms süresinde çözdürülmüştür.

Modelin enerji sönümleme miktarı, toplam yer değiştirme miktarı, yolcuya iletilen kuvvet gibi grafikleri elde etmek amacıyla 120 ms boyunca eşit zaman aralıkları için 50'şer adet değer Abaqus çıktı dosyalarına kaydedilmiştir.

Ön çarpışma kolları ile kapakları arasındaki bağlantıyı sağlamak amacıyla çarpışma kolları ve flanşların arasında punta kaynak tanımı yapılmıştır. Punta kaynaklarının konumunu belirlemek amacıyla FCA punta kaynak standartları baz alınmış ve Abaqus yazılımında "Rijid MPC" tipinde 27 adet punta kaynak tanımı Şekil 5'te gösterilen bölgelerde oluşturulmuştur.

Abaqus dinamik analizlerinde 'self contact'a izin verdiği için çarpışma analizlerinde temas eden tüm bileşenler arasında 0,15 sürtünme katsayısına sahip bir genel temas tanımlanmıştır.

Çarpışma senaryosunu oluşturmak için rijit duvara $64 \mathrm{~km} / \mathrm{h}$ ilk hız tanımlanmış ve çarpışma kollarının arka tarafındaki kesit yüzeylerini de tüm dügüm noktalarında ankastre mesnet olarak tanımlanmıştır (Şekil 5).

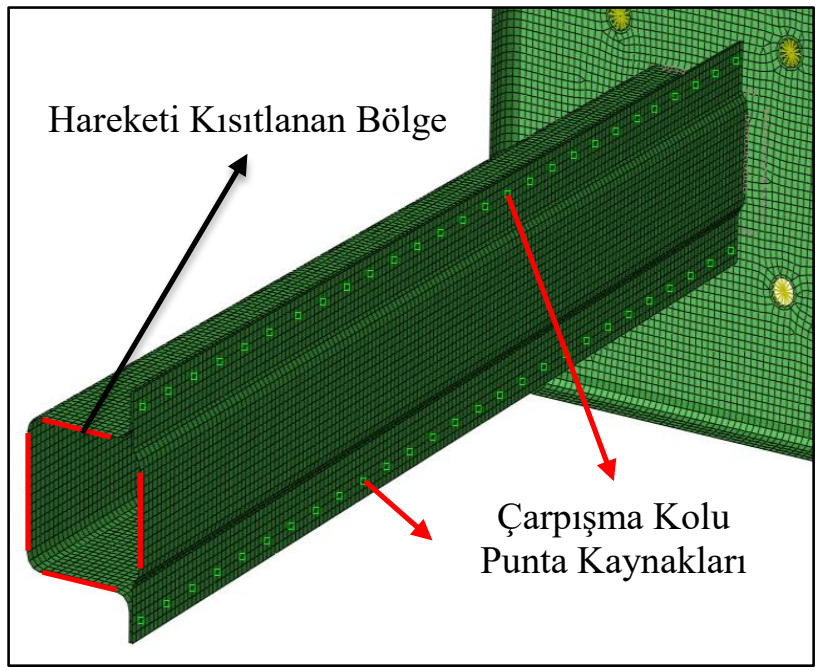


Şekil 5:

Ön çarpışma bölgesinin ön işleme modeli (Hypermesh-Abaqus)

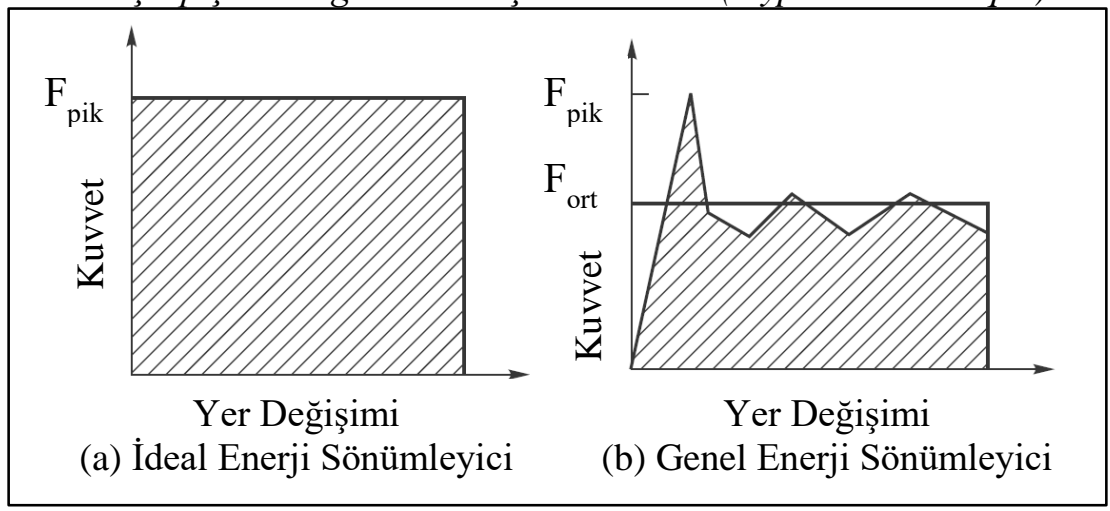

Şekil 6:

(a) İdeal enerji emilim grafiği (b) genel enerji emilim grafiği (Rao, 2016)

Elemanların çarpışma performansları, çarpışma kuvvet verimliliği (CFE) oranı hesap edilerek değerlendirilmiştir. Çarpışma anında elemanda ortaya çıkan ortalama kuvvetin maksimum kuvvete oranı (Şekil 6) çarpışma kuvveti verimliliği olarak isimlendirilir ve aşağıdaki formülle ifade edilir:

$$
C F E=\frac{F_{\text {ort }}}{F_{\text {pik }}}
$$

Çarpışma kuvveti verimlilik katsayısı (CFE), enerji sönümleyici elemanların ezilmesi sonucu açığa çıkan yavaşlama ivmesinin yolcuda oluşturduğu hasarı incelemede yardımcı olmaktadır. CFE oranı ne kadar 1'e yakın olursa kuvvet-yer değiştirme grafiği o kadar düzleşir. Düşük CFE, görece yüksek pik (maksimum) kuvvetlerine sebep olduğu için çarpışma anında yolcu ve araç bileşenleri üzerindekindeki risk artmaktadır. Dolayısıyla, CFE oranı 1'e yakın olan kuvvet-yer değişimi grafikleri ile en yüksek çarpışma performans verimliliği sağlanmış olmaktadır. Ayrıca CFE oranı, çarpışma sonucunda iletilen kuvvetin karakteristik özelliğinin yorumlanması için de kullanılmaktadır (Rao ve diğ., 2016).

\section{BULGULAR VE TARTIŞMA}

Simülasyonlarda $64 \mathrm{~km} / \mathrm{h}$ ilk hıza, $\% 100$ ofsete ve $1000 \mathrm{~kg}$ kütleye sahip rijit duvar, çarpışma bölgesine dik bir şekilde çarptırılmıştır. Elde edilen sonuçlar, enerji sönümleme miktarı eğrileri, toplam yer değişimi eğrisi, yolcu kabinine iletilen kuvvet eğrileri ve ön çarpışma kollarının çarpışma kuvvet verimliliği (CFE) eğrileri baz alınarak değerlendirilmiştir

Şekil 7'de ön çarpışma bölgesinde sönümlenen enerjinin (FEE340 ve DP600 malzemeleri için) zamana bağlı değişimi verilmiştir. $2,6 \mathrm{~mm}$ kalınlığında ve çarpışma kollarında FEE340 malzemesi kullanılan model $58 \mathrm{~ms}$ 'de açığa çıkan tüm enerjiyi sönümlediği görülmüştür. Aynı kalınlığa sahip, çarpışma kollarında DP600 malzemesi kullanılan model ise $48 \mathrm{~ms}$ 'de aynı miktarda enerjiyi sönümlemiştir. Şekil 8'de FEE340 ve DP600 malzemeleri için aracın ön ucunun yer değiştirmesi (aracın ezilmesi) zamana bağlı olarak verilmiştir. 2,6 mm kalınlığında ve çarpışma kollarında FEE340 malzemesi kullanılan model 58 ms süresinde maksimum 579,5 mm toplam yer değişimi görülmüş, buna karşın aynı kalınlıktaki DP600 çarpışma kollarında 48 ms süresinde maksimum 521,7 mm toplam yer değişimi oluşmuştur. Yazılımda toplam yer değiştirme, rijit duvarın üzerindeki bir referans noktası üzerinden hesaplanmıştır.

Şekil 4 te verilen Gerilim-Gerinim eğrilerinden de anlaşılacağ FEE340'a göre daha mukavemetli bir çelik olduğundan, DP600 malzemesi kullanılan ön 
çarpışma kolu yaklaşık \%10 daha az ezilmekte ve çarpışma $\% 20$ daha kısa sürede tamamlanmaktadir.

Şekil 9'da ön çarpışma kollarında FEE340 ve DP600 malzemelerinin kullanıldığ1 araç modellerinde, her bir elemanın sönümlediği enerji değerleri görülmektedir. Şekilden FEE340 malzemesinin kullanıldığı araç modelinde tüm elemanların sönümlediği toplam enerjinin 161,3 $\mathrm{kJ}$ olduğu görülmektedir. Bu enerjinin 12,3 kJ tampon traversinde, 26,8 kJ çarpışma kutusunda ve 118,6 kJ çarpışma kollarında sönümlenmektedir.

Simülasyon sonucunda, ön tampon traversinin çarpışma sonucu oluşan enerjinin \% 7,6 'sını, çarpışma kutularının \%16,6'sını ve çarpışma kollarının \%73,5'ini sönümlediği gözlenmiştir. Çarpışma kolunun sönümlediği enerji oranı yapılan literatür araştırmaları sonuçlarına uyumlu olduğu gözlenmiştir (Ghannam ve diğ., 2002)

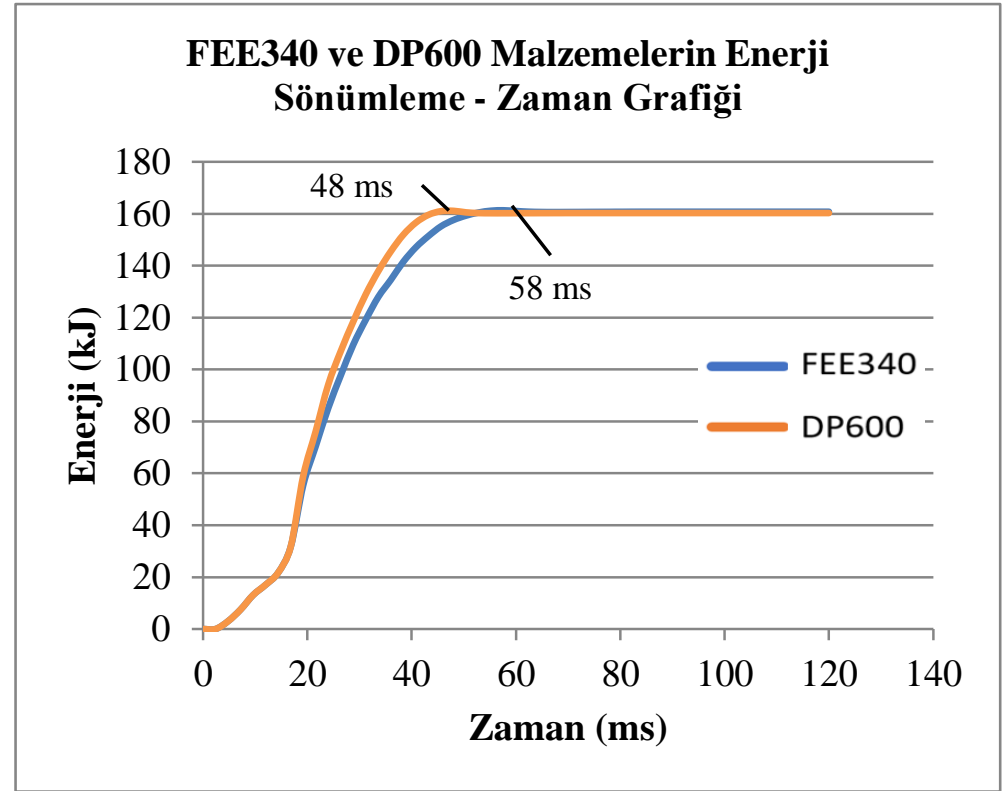

Şekil 7:

FEE340 ve DP600 çeliğinin enerji sönümleme miktarı ĕgrisi

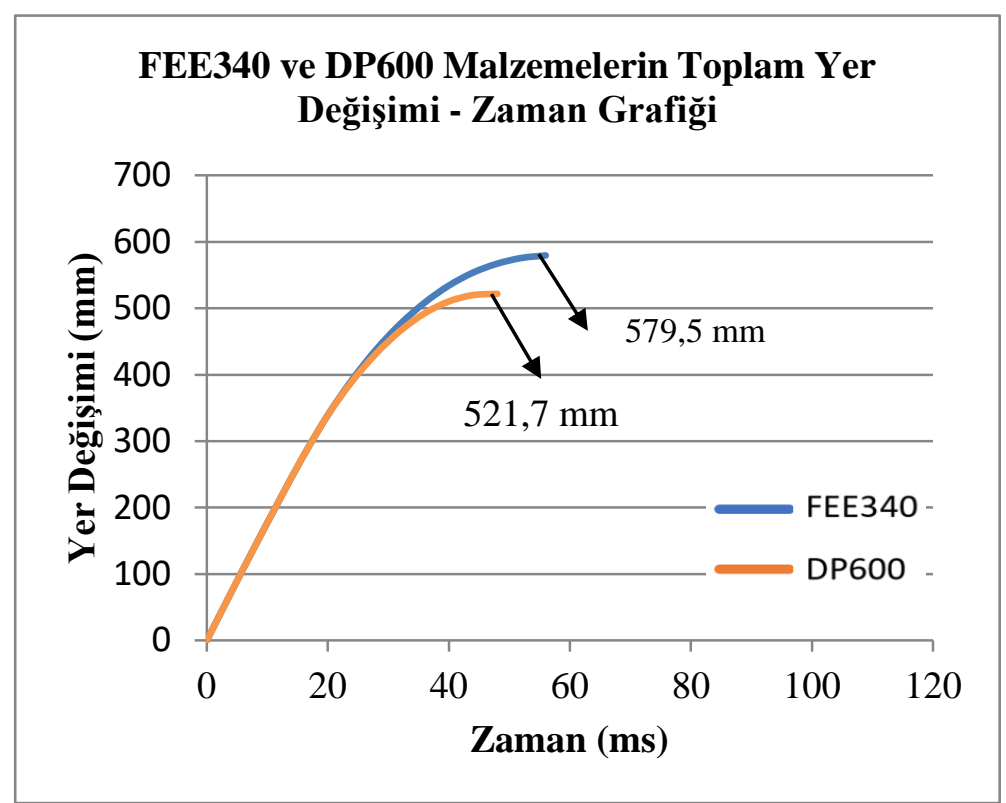


Şekil 8:

FEE340 ve DP600 çeliğinin zamana bağlı toplam yer değiştirme ĕgrisi

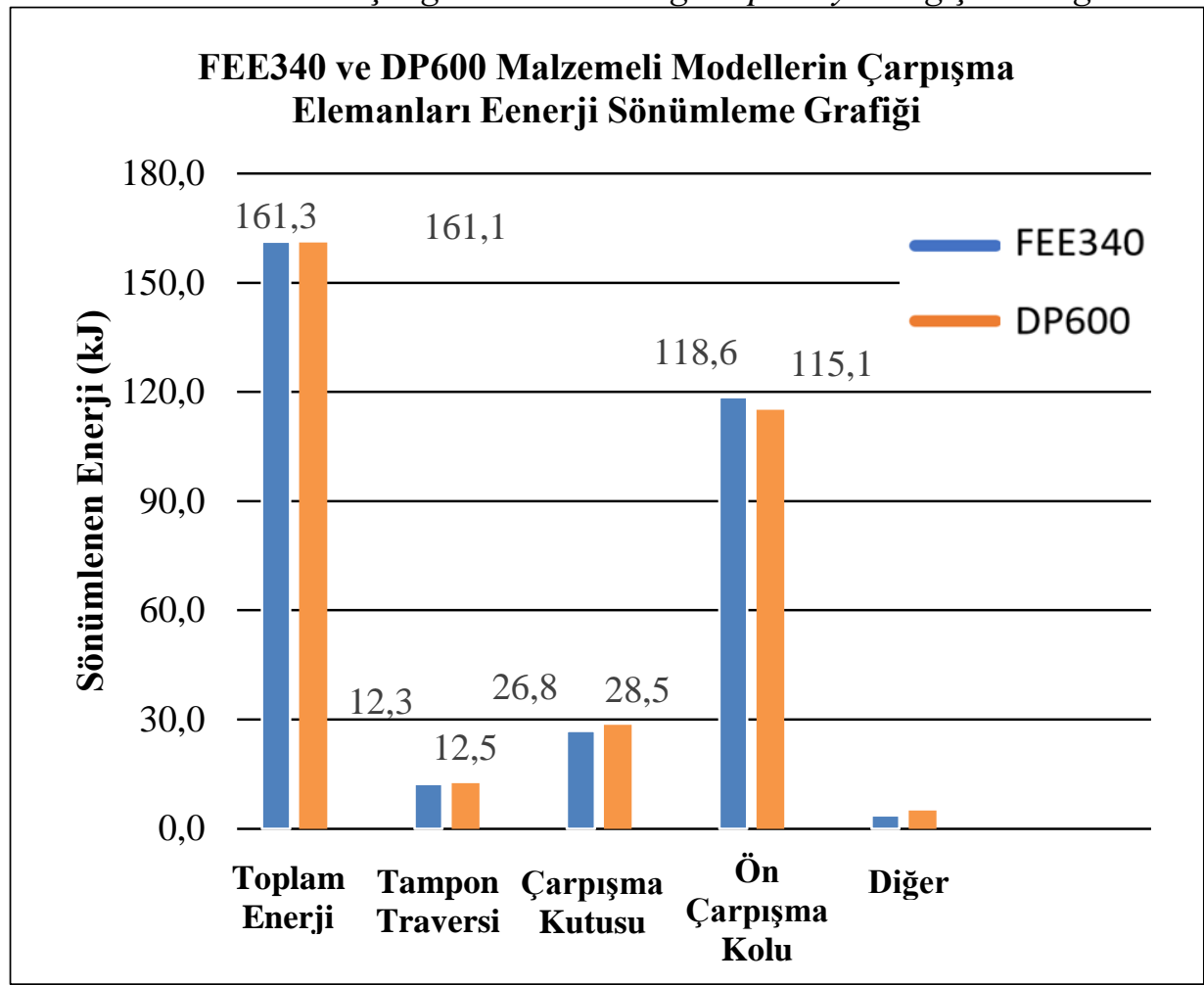

Şekil 9:

FEE340 ve DP600 malzemesine sahip çarpışma bölgesi elemanlarının sönümlediği enerjiler

Şekil 10'da FEE340 ve DP600 malzemeleri için ön çarpışma kolundan yolcu kabinine iletilen kuvvetin yer değiştirmeye bağlı değeri verilmiştir. Şekilden, FEE340 malzemesi için yolcu kabinine iletilen maksimum kuvvetin 531,9 kN olduğu, DP600 malzemesi için yolcu kabinine iletilen maksimum kuvvetin ise 701,2 kN olduğu görülmektedir.

Şekil 11'de sadece ön çarpışma kolunda ortaya çıkan kuvvetin, ön çarpışma kolunda oluşan yer değiştirmeye bağlı değişimi gösterilmiştir. Şekilde ayrıca ön çarpışma kolunda kullanılan FEE340 ve DP600 malzeme modellerin CFE sonuçları ortalama ve maksimum kuvvet değerleriyle birlikte görülmektedir

Malzeme farkının çarpışma kolları üzerindeki etkilerini daha detaylı göstermek amacıyla sadece çarpışma kollarının çalıştığ $290 \mathrm{~mm}$ ile $580 \mathrm{~mm}$ yer değiştirme aralığındaki bir kesit alınmıştır. Şekil 11'de, FEE340 malzemesi için yolcu kabinine iletilen ortalama kuvvetin 400,6 $\mathrm{kN}$, DP600 malzemesi için ise yolcu kabinine iletilen ortalama kuvvetin 533,7 kN olduğu görülmektedir. FEE340 malzemesi için maksimum kuvvet ile ortalama kuvvet arasındaki fark 131,3 kN iken DP600 malzemesi için bu fark 167,5 kN olduğu görülmüştür. Grafik üzerinden hesap edilen integral toplamının yardımı ile CFE oranı FEE340 için 0,753 ve DP600 için 0,761 olarak hesap edilmiştir. Yazılımda yolcu kabinine iletilen kuvvet, ön çarpışma kolu ile yolcu kabinini birleştiren düğüm noktalarından okunmuştur (Şekil 5). Çalışmada FEE340 malzemesi için elde edilen yolcu kabinine iletilen maksimum kuvvet, 2016 y1lında George Mason Üniversitesinde Toyota Yaris modeli araç üzerinde yapılan deneysel çalışmanın verdiği $575 \mathrm{kN}$ luk maksimum kuvveti değeri ile uyumlu olduğu görülmektedir. 


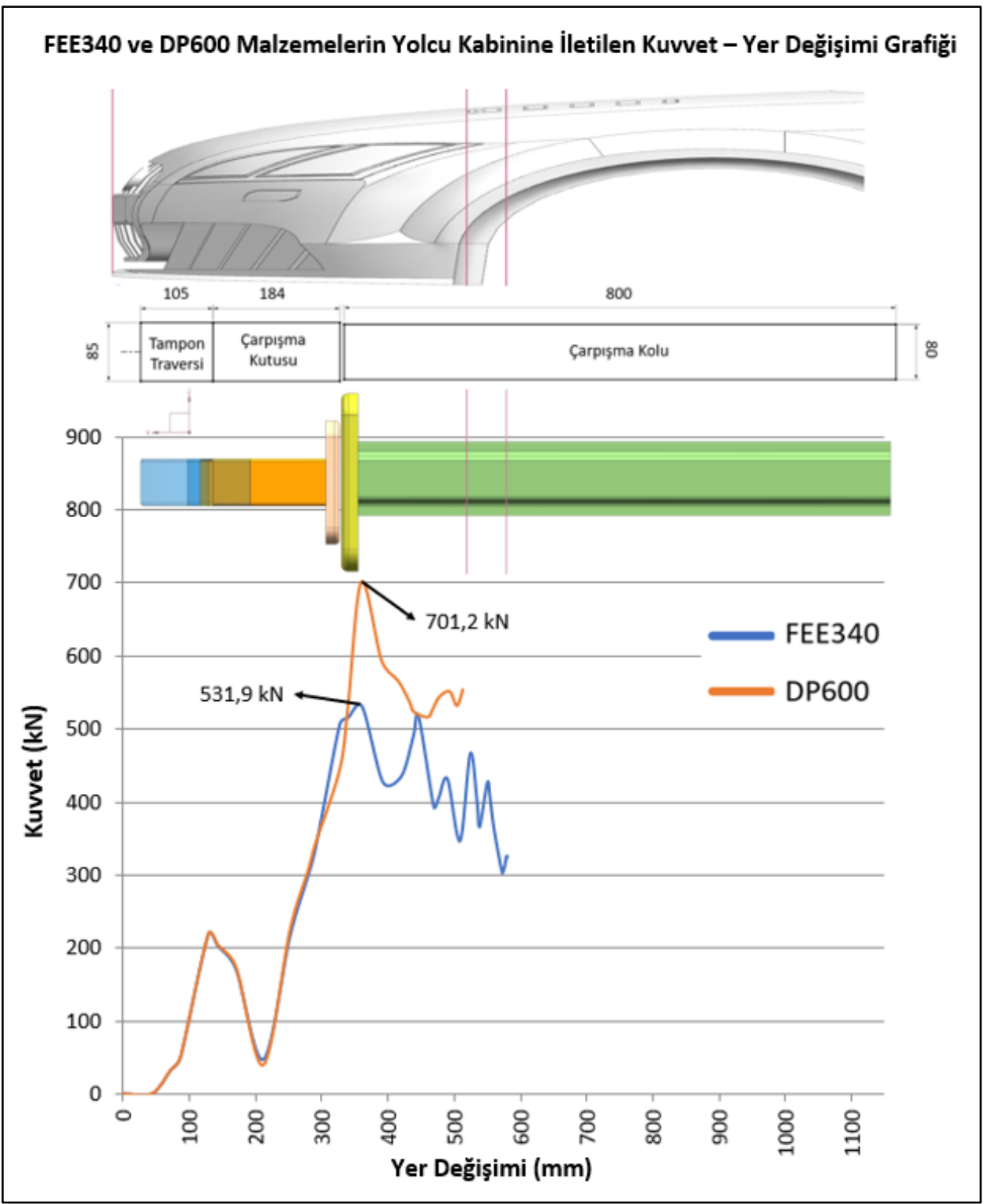

\section{Şekil 10:}

FEE340 ve DP600 çelik malzemeleri için yolcu kabinine iletilen kuvvetin aracın çarpışma elemanlarının toplam yer değişimi (aracın ezilmesi) ile değişimi

Şekil 12'de yolcu kabini yavaşlama ivmesinin aracın çarpışma elemanlarının toplam yer değiştirmesi (aracın ezilmesi) ile değişimi görülmektedir. FEE340 malzemesi için $361 \mathrm{~mm}$ yer değiştirmede 49,9 g lik bir maksimum ivmenin, DP600 malzemesi için ise $361 \mathrm{~mm}$ yer değiştirmede $60,8 \mathrm{~g}$ lik bir maksimum ivme değerinin ortaya çıktığ görülmektedir. Çalışmada elde edilen maksimum ivmenin, 2013 yılında Tahan ve diğ. yaptığı benzer bir çalışmada $47 \mathrm{~g}$ maksimum ivme değeri ile uyumlu olduğu görülmektedir.

Şekil 13'de ön çarpışma kolunda kuvvetin pik yaptığı (soldaki) ve çarpışma kolunun en fazla ezildiği (sağdaki) anlardaki görüntüleri verilmiştir. Her iki malzeme için de ön çarpışma kolu ilk burkulmayı tamamladığında yolcuya iletilen kuvvetin pik yaptığı görülmektedir. Ayrıca FEE340 malzemesi ile üretilen ön çarpışma kolunun $64 \mathrm{~km} / \mathrm{h}$ hızındaki rijit duvarı durdurmak 
için 4 adet yerel burkulma gerçekleştirdiği buna karşın DP600 malzemesi ile üretilen ön çarpışma kolunun ise 3 adet yerel burkulma gerçekleştirdiği görülmektedir.

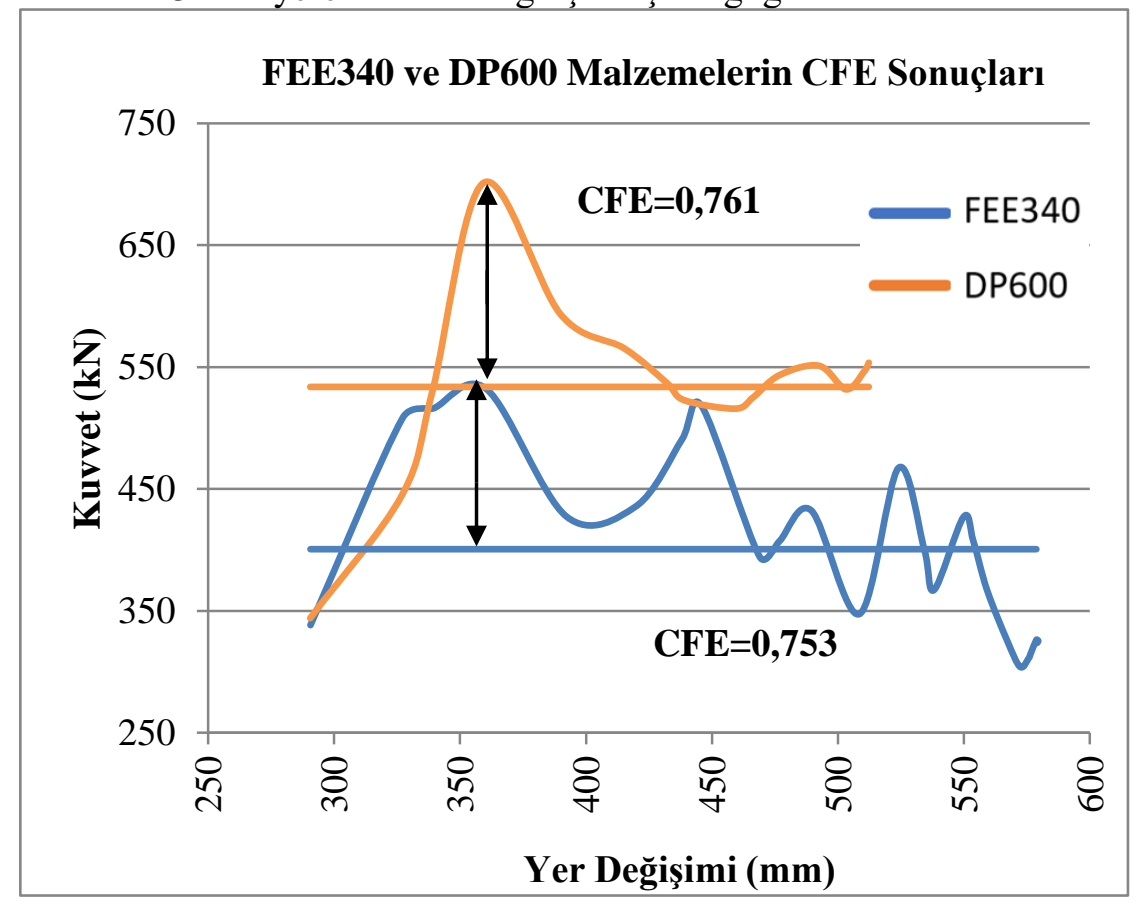

Şekil 11:

FEE340 ve DP600 çelik malzemeleri için ön çarplşma kolu kuvvet-yer değişimi eğrisi ve CFE oranlart

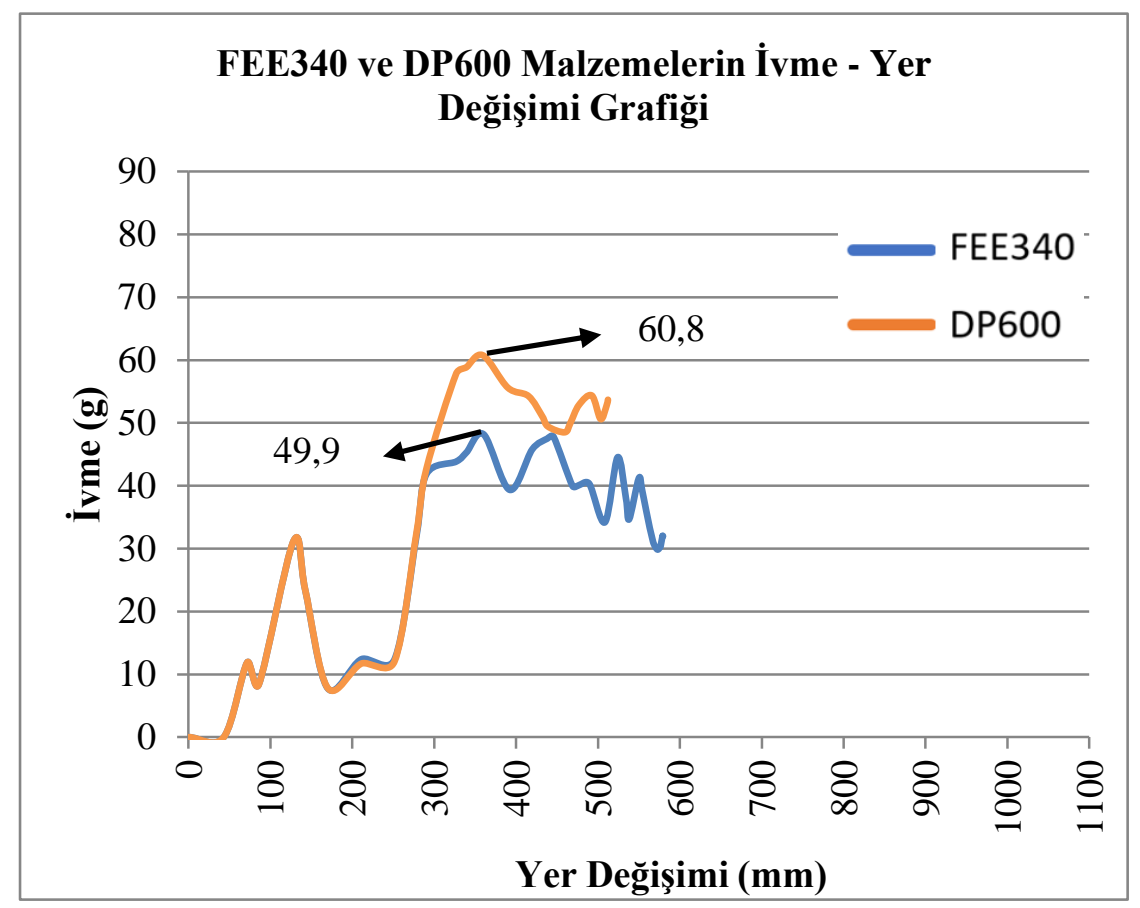

\section{Şekil 12:}

Yolcu kabini yavaşlama ivmesinin aracın çarpışma elemanlarının toplam yer değiştirmesi (aracın ezilmesi) ile değişimi 


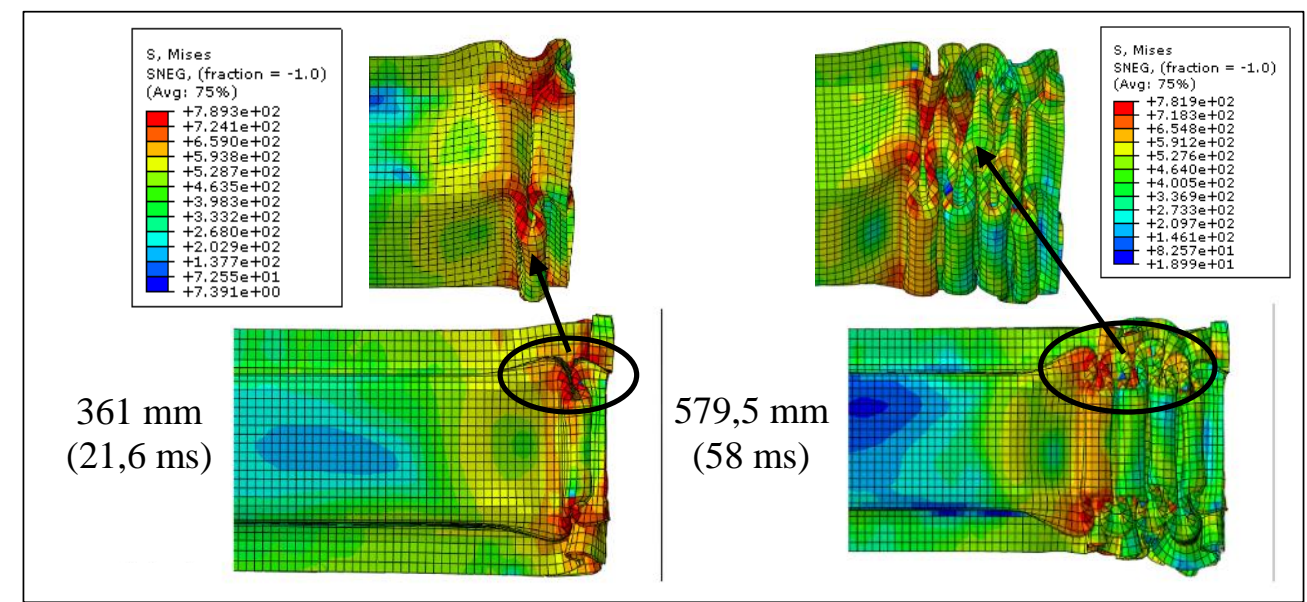

(a)

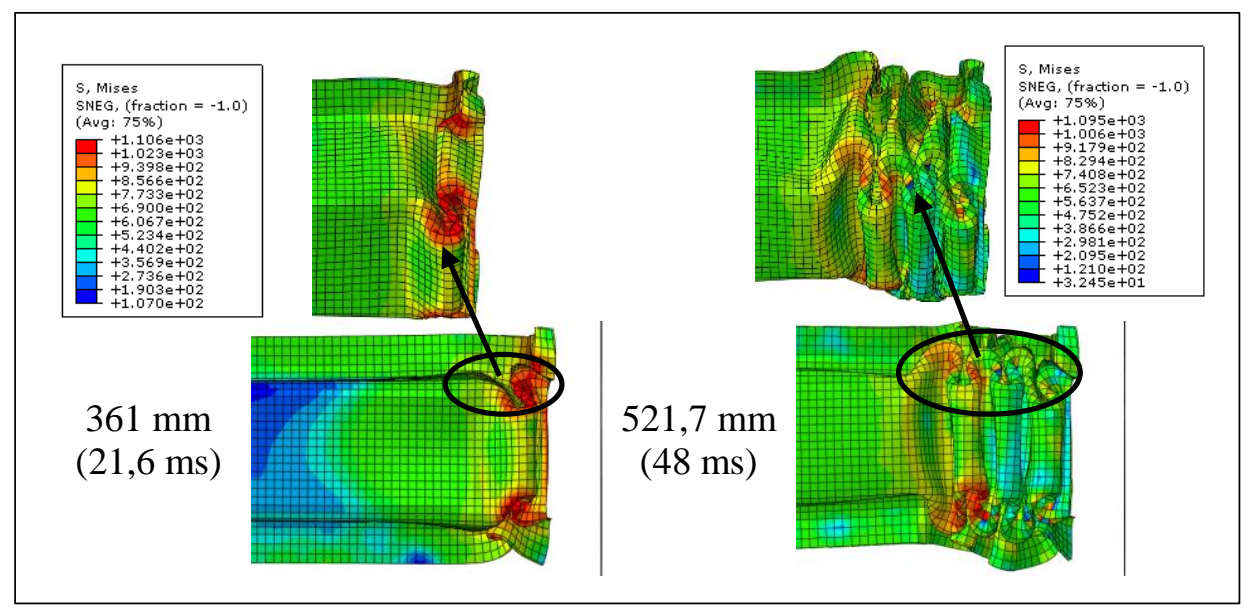

(b)

Şekil 13:

Ön çarpışma kolunda kuvvetin pik yaptığl (soldaki) ve çarpışma kolunun en fazla ezildiği (sağdaki) durumlar. a. FEE340, b. DP600

\section{SONUÇ VE ÖNERILER}

$\mathrm{Bu}$ çalışmada otomobil sektöründe s1k kullanılan FEE340 ve DP600 çeliklerinin ön çarpışma kollarında kullanımı üzerine analizler yapılmış ve otomobil çarpışma performansına olan etkileri incelenmiştir. Analizler sonucunda, çarpışma kollarında FEE340 malzeme kullanılmasının yolcu kabinine iletilen kuvveti önemli bir miktarda azalttığı, buna karşın yer değiştirme miktarını arttırdığı görülmüştür. Bunun yanında, FEE340 malzemesinin kullanılmasının pik kuvvet ile ortalama kuvvet arasındaki farkın azaldığı gözlenmiştir. FEE340 ve DP600 malzemeye sahip çarpışma kollarının CFE katsayı değerlerinin birbirine yakın olduğu hesaplanmiştır.

Simülasyonlarda çarpışmanın ilk anlarında (çarpışma kollarında ilk burkulma tamamlanırken) pik kuvvetin oluştuğu görülmektedir. Buna karşın, çarpışma kollarının uç kısımlarına ezilme başlatıcı formlar verilerek, çarpışmanın ilk anlarında oluşan bu pik kuvvet değerini düşürmek mümkündür. Bu etkiyi oluşturacak özel forma sahip ön çarpışma kolları ve ön çarpışma kollarında alüminyum köpük takviyesi gelecek dönem için oldukça ilginç çalışma konularıdır. Bunun yanında daha yüksek mukavemet değerlerine sahip DP600 malzemesinin 
farklı et kalınlıkları test edilerek ön çarpışma kolunda kütle optimizasyonu üzerine çalışmalar yürütülebilir.

\section{KAYNAKLAR}

1. Bois Paul Du, Chou Clifford C., Fileta Bahig B. \& King Albert I. (2004). Vehicle Crashworthiness and Occupant Protection. American Iron and Steel Institute 2000 Town Center Southfield,Michigan 48075.

2. Chiandussi, G., Avalle, M. (2002) Maximization of the crushing performance of a tubular device by shape optimisation, Computers and Structures, 80, 2425-2432.

3. Deb, A., Gunti, R. S., Chou, C., \& Dutta, U. (2015). Use of truncated finite element modeling for efficient design optimization of an automotive front end structure (No. 201501-0496). SAE Technical Paper.

4. Edwards, M. J., Davies, H., Thompson, A., \& Hobbs, A. (2003). Development of test procedures and performance criteria to improve compatibility in car frontal collisions. Proceedings of the Institution of Mechanical Engineers, Part D: Journal of Automobile Engineering, 217(4), 233-245.

5. Ensarioglu C., Gulcimen Cakan B., Reis M., Koluk H., Celik H., Uguz A., Cakir M. C. (2018). Reinforcement of a Thermoplastic Crash-Box with Aluminum Foam and Tie Beams. Academic Conference on Engineering, IT and Artificial Intelligence (AC-EITAI 2018), Prag.

6. Eren, I., Gür, Y., \& Aksoy, Z. (2009). Finite element analysis of collapse of front side rails with new types of crush initiators. International journal of automotive technology, 10(4), 451-457.

7. Fekete, J. R., Stibich, A. M., \& Shi, M. F. (2001). A comparison of the response of HSLA and dual phase sheet steel in dynamic crush (No. 2001-01-3101). SAE Technical Paper.

8. George Mason University, (2016). 2010 Toyota Yaris Finite Element Model Validation Detail Mesh, Center for Collosion Safety and Analysis. (Doi: 10.13021/G8CC7G)

9. Ghannam, M. Y., Niesluchowski, M., \& Culkeen, P. M. (2002). Analysis of a Frontal Rail Structure in a Frontal Collision (No. 2002-01-0688). SAE Technical Paper.

10. Gulcimen Cakan B., Reis M., Ensarioglu C., Koluk H., Yeni H., Uguz A., Cakir M. C. (2018). Termoplastik çarpışma kutularında alüminyum köpük takviyesinin çarpışma karakteristiğine etkisi. $18^{\text {th }}$ International Conference on Machine Design and Production, 36 July, Eskişehir.

11. Liu, X. T., Liu, C. H., Shi, S. L., Zhao, L. H., \& Huang, H. (2010, February). The analysis of front rail crash on mini-bus chassis. In Computer and Automation Engineering (ICCAE), 2010 The 2nd International Conference on (Vol. 2, pp. 14-16). IEEE.

12. Öztürk, İ., \& Necmettin, Kaya (2008). Otomobil ön tampon çarpışma analizi ve optimizasyonu. Uludağ University Journal of The Faculty of Engineering, 13(1).

13. Ramazani, A., Mukherjee, K., Abdurakhmanov, A., Prahl, U., Schleser, M., Reisgen, U., \& Bleck, W. (2014). Micro-macro-characterisation and modelling of mechanical properties of gas metal arc welded (GMAW) DP600 steel. Materials Science and Engineering: A, $589,1-14$. 
Uludağ Üniversitesi Mühendislik Fakültesi Dergisi, Cilt 24, Sayı 1, 2019

14. Rao Lakshmana C., Narayanamurthy V., \& Simha K. R. Y. (2016). Applied Impact Mechanics . Ane Books Pvt. Ltd. (ISBN : 978-11-1924-180-5).

15. Tahan, F. J., Park, C. K., Morgan, R. M., Cui, C., Brar, B., Shanks, K., \& Kan, C. D. (2013). The Effect of Reduced Mass on Frontal Crashworthiness. Proceedings of the IRCOBI Conference, 2013. 
